\title{
MIXED CONVECTION IN MHD FLOW AND HEAT TRANSFER RATE NEAR A STAGNATION-POINT ON A NON-LINEAR VERTICAL STRETCHING SHEET
}

\author{
O.J. FENUGA* \\ Department of Mathematics, University of Lagos \\ Akoka, Lagos, NIGERIA \\ E-mail: ofenuga@unilag.edu.ng \\ A.R. HASSAN \\ Department of Mathematics, Tai Solarin University of Education \\ Ogun State, NIGERIA \\ E-mail: anthonyhassan72@yahoo.co.uk \\ P.O. OLANREWAJU \\ Department of Mathematics and Statistics, Federal University \\ Wukari, TarabaState, NIGERIA \\ E-mail: oladapo_anu@yahoo.ie
}

\begin{abstract}
This work investigates the mixed convection in a Magnetohydrodynamic (MHD) flow and heat transfer rate near a stagnation-point region over a nonlinear vertical stretching sheet. Using a similarity transformation, the governing equations are transformed into a system of ordinary differential equations which are solved numerically using the fourth order Runge-Kutta method with shooting technique. The influence of pertinent flow parameters on velocity, temperature, surface drag force and heat transfer rate are computed and analyzed. Graphical and tabular results are given to examine the nature of the problem. The heat transfer rate at the surface increases with the mixed convection.
\end{abstract}

Key words: mixed convection, MHD flow, heat transfer rate, stagnation -point, non-linear vertical stretching sheet.

\section{Introduction}

Magnetohydrodynamic stagnation point flow and heat transfer on a stretching sheet has many practical applications in engineering and industries including electronic and nuclear processes, polymer or metal extrusion, oil reservoir, geothermal systems, thermal energy storage device, ground water systems, energy storage units, biological transportation, micro-MHD pumps, high temperature plasmas, drawing of plastic sheets, liquid coating on photographic films, glass fiber production, electronic cooling, aerodynamics, continuous casting of metals, hot rolling of papers and wire drawing. The mixed convection in stagnation point is of significance in fluid mechanics because when the buoyancy forces due to the temperature difference between the surface and the free stream are large, the flow and the thermal fields are greatly affected.

There are many research works on MHD mixed convection stagnation point flow over vertical stretching sheet. Alli et al. [1] studied a steady laminar, Magnetohydrodynamic mixed convection stagnation point flow of an incompressible fluid over a vertical stretching sheet using an implicit finite difference scheme. The influence of an unsteady flow near a stagnation point comprising of Eyring-Powell nano liquid over a convectively heated stretched surface using the shooting technique was investigated by Ali and Zaib [2]. The flow and heat transfer over a nonlinearly stretching sheet was investigated by Akyildiz and Siginer [3] using a Legendre spectral method. Asraf and et al. [4], Dhanai et al. [8] and Mabood et al. [15] analyzed the boundary layer flow and heat transfer on a nonlinearly shrinking/stretching sheet immersed in a nano fluid. Akyildiz and Siginer [5] studied the

\footnotetext{
* To whom correspondence should be addressed
} 
similarity solution of the boundary layer equations for a nonlinearly stretching sheet. Das et al. [6] and Makinde et al. [18], investigated the Magnetohydrodynamics boundary layer flow over a vertical stretching/shrinking sheet in a nano-fluid. Das et al. [7] investigated the effects of homogeneous-heterogeneous reactions on a stretching two dimensional mixed convection stagnation point boundary layer flow of an incompressible, viscous, electrically conducting, nonlinear, radiative heat transfer and chemically reacting copper-water nano fluid towards a linear stretching sheet using the spectral local linearization method. Fauzi et a.l [9] analyzed the effects of slip parameters $\mathrm{A}$ and $\mathrm{B}$ on a steady stagnation-point flow and heat transfer due to a shrinking sheet in a viscous and incompressible fluid by using shooting method. Govardhan et al. [10], considered MHD effects on a mixed convection flow of an incompressible micro-polar fluid over a stretching sheet. There was a smooth transition from small-time solution to large-time solution. Ishak et al. [11] studied a steady, two dimensional, Magnetohydrodynamic stagnation-point flow towards a stretching sheet with variable surface temperature using a finite difference scheme known as Keller-Box method. Ishak et al. [12] studied a two dimensional Magnetohydrodynamic flow of a viscous, incompressible and electrically conducting fluid over a stretching vertical surface with constant wall temperature using the Keller-box method. Khan et al. [13], investigated viscous dissipation effect on a Magnetohydrodynamics stagnation-point ferro fluid flow and heat transfer towards a stretching sheet. Khan et al. [14] developed a mathematical model to study the Magnetohydrodynamic flow of a viscous fluid due to a nonlinear stretching cylinder in the presence of viscosity and thermal slip conditions with effects of viscous dissipation and Joule heating. Maboodet al [15] provided a numerical study for an MHD laminar boundary layer flow with heat and mass transfer of an electrically conducting water-based nanofluid over a nonlinear stretching sheet with viscous dissipation effect. Mahatha et al. [16] considered the flow of a viscous, incompressible and electrically conducting nano fluid flow over a stretching sheet under the influence of a transverse magnetic field with effect of nonlinear thermal radiation, Newtonian heating and partial velocity slip. Makinde [17] considered the heat and mass transfer by an MHD mixed convection stagnation point flow towards a vertical plate embedded in a highly porous medium with radiation and internal heat generation. Matta and Gajjela [19] investigated the order of chemical reaction and convective boundary conditions on thermo-solutal behavior of Magnetohydrodynamic fluid flow above a stretching sheet. Medikare et al. [20] analyzed an MHD stagnation point flow of a Casson fluid over a nonlinearly stretching sheet with viscous dissipation using the finite difference technique called the Keller- box method. Nagaraju and Ramana Murthy [21] considered the flow of an incompressible, electrically conducting couple stress fluid generated by longitudinal and torsional oscillation of a porous circular cylinder subjected to suction/injection at the surface of the cylinder and in the presence of a radial magnetic field using the finite difference method. Nandeppanavar et al. [22] studied the heat transfer characteristics of a stagnation point flow of an MHD flow over a nonlinearly moving plate with momentum and thermal slip effects in the presence of non-uniform heat source/sink using the fourth order Runge Kutta method. Shen et al. [23] studied the problem of a Magnetohydrodynamics mixed convection flow near a stagnation-point region over a nonlinear stretching sheet with velocity slip and prescribed surface heat flux using the homotopy analysis method. Shateyi and Mabood [24] analysed numerically the MHD mixed convection stagnation-point flow towards a nonlinearly stretching vertical sheet in the presence of thermal radiation and viscous dissipation using the Runge Kutta Fehlberg fourth-fifth order method. Shateyi and Makinde [25] studied the effects of viscous dissipation on a hydromagnetic stagnation-point flow towards a radially stretching convectively heated disk. Shateyi and Marewo [26] studied the Magnetohydrodynamic mixed convection stagnation-point flow and heat transfer of an incompressible, viscous fluid over a vertical stretching sheet.

This work extends the work of Shen et al. [23] by considering mixed convection in an MHD flow and heat transfer rate near a stagnation point on a nonlinear vertical stretching sheet.

\section{Materials and method}

This work considers the mixed convection in a steady, MHD, two-dimensional viscous, incompressible, electrically conducting flow and heat transfer rate near a stagnation point over a nonlinear vertical stretching sheet. The flow is confined to the region $y \geq 0$, where $y$ is the coordinate measured normal to the stretching sheet. The fluid is considered to be influenced by a transverse uniform magnetic field $B$, normal to the surface $y=0$. The flow model along with the coordinate system is shown in the figure below. 


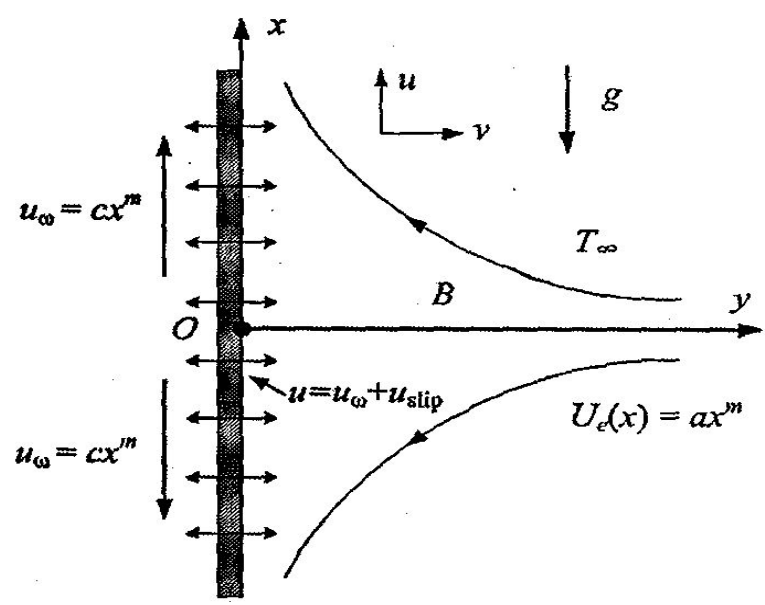

Fig.1. Physical model and coordinate system.

It is assumed that the sheet stretches with velocity $u_{w}(x)=c x^{m}$ and the external velocity is prescribed as $u_{e}(x)=a x^{m}$ where $a$ and $c$ are positive constants. The constant $m$ is the nonlinearity parameter with $m=1$ for the linear case and $m \neq 1$ for the nonlinear case. Under the boundary layer approximation, the basic continuity, momentum and energy equations describing the flow are

$$
\begin{aligned}
& \frac{\partial u}{\partial x}+\frac{\partial v}{\partial y}=0 \\
& u \frac{\partial u}{\partial x}+v \frac{\partial u}{\partial y}=u_{e} \frac{d u_{e}}{d x}+v \frac{\partial^{2} u}{\partial y^{2}}+\frac{\sigma B^{2}(x)}{\rho}\left(u_{e}-u\right)+g \beta\left(T-T_{\infty}\right), \\
& \rho c_{p}\left(u \frac{\partial T}{\partial x}+v \frac{\partial T}{\partial y}\right)=\kappa \frac{\partial^{2} T}{\partial y^{2}}-\frac{\partial q_{r}}{\partial y}+\mu\left(\frac{\partial u}{\partial y}\right)^{2}
\end{aligned}
$$

where $u$ and $v$ are the velocity components in the $x$ and $y$ directions, $v$ is the kinematic viscosity, $u_{e}$ is the free stream or external velocity, $\rho$ is the fluid density, $\sigma$ is the electrical conductivity, $B(x)$ is the transverse magnetic field, $g$ is the acceleration due to gravity, $\beta$ is the thermal expansion coefficient, $T$ is the fluid temperature, $c_{p}$ is the specific heat at constant pressure, $\kappa$ is the thermal conductivity of the fluid under consideration, $q_{r}$ is the radiative heat flux and $\mu$ is the dynamic viscosity.

The relevant boundary conditions are

$$
\begin{aligned}
& u=u_{w}(x)+\frac{2-\sigma_{v}}{\sigma_{v}} \lambda_{0} \frac{\partial u}{\partial y}, \quad v=v_{w}(x), \quad \frac{\partial T}{\partial y}=-\frac{q_{w}(x)}{k} \quad \text { at } \quad y=0, \\
& u \rightarrow u_{e}(x), \quad T \rightarrow T_{\infty} \quad \text { as } \quad y \rightarrow \infty
\end{aligned}
$$

where $\sigma_{v}$ is the tangential momentum accommodation coefficient, $\lambda_{0}$ is the mean free path, $v_{w}(x)$ is the suction (or injection) velocity, $\kappa$ is the thermal conductivity and $q_{w}(x)$ is the surface heat flux, $\sigma$ is the electrical conductivity. We introduce the following similarity variables in the transformation

$$
\eta=y \sqrt{\left(\frac{a}{v}\right)} x^{\frac{(m-1)}{2}}, \quad \psi=\sqrt{a v} x^{\frac{(m+1)}{2} f(\eta)} \quad \text { and } \quad \theta=\sqrt{\left(\frac{a}{v}\right)} \frac{k\left(T-T_{\infty}\right)}{q_{0} x^{2 m-1}}
$$

where $\psi$ is the stream function. Equation (2.1) is satisfied by introducing $\psi$ such that 


$$
u=\frac{\partial \psi}{\partial y} \quad \text { and } \quad v=-\frac{\partial \psi}{\partial x} .
$$

Using the similarity variables in Eq.(2.6), the $x$ and $y$ velocity components are given as

$$
u=a x^{m} f^{\prime}(\eta)=u_{e} f^{\prime}(\eta), \quad v=-\sqrt{a v} x^{\frac{(m-1)}{2}}\left[\left(\frac{m+1}{2}\right) f(\eta)+\left(\frac{m-1}{2}\right) \eta f^{\prime}(\eta)\right] .
$$

To obtain similarity solutions, $B(x), v_{x}(x)$ and $q_{w}(x)$ are taken as

$$
B(x)=B_{o} x^{\frac{m-1}{2}}, \quad v_{w}=-\frac{\sqrt{a v(m+1)}}{2} x^{\frac{m-1}{2}} S, \quad q_{w}(x)=q_{0} x^{\frac{5 m-3}{2}}
$$

where $B_{0}, S$ and $q_{0}$ are constants. It should be noted that $S>0$ corresponds to injection and $S<0$ corresponds to suction. Substituting (2.6) into (2.2) and (2.3), the following nonlinear ordinary differential equations are obtained

$$
\begin{aligned}
& f^{\prime \prime \prime}+\left(\frac{M+1}{2}\right) f^{\prime \prime}+m\left(1-f^{\prime 2}\right)+M\left(1-f^{\prime}\right)+\lambda \theta=0 \\
& \frac{1}{\operatorname{Pr}}\left(1+\frac{4}{3} R d\right) \theta^{\prime \prime}-\left(\frac{m+1}{2}\right) f \theta^{\prime}-(2 m-1) f^{\prime} \theta+\operatorname{Ec}\left(f^{\prime \prime}\right)^{2} \theta=0 .
\end{aligned}
$$

Subject to the boundary conditions (2.12) and (2.13) below

$$
\begin{aligned}
& f(0)=S, \quad f^{\prime}(0)=\epsilon+f^{\prime \prime}(0), \quad \theta^{\prime}(0)=-1, \\
& f^{\prime}(\infty) \rightarrow 1, \quad \theta(\infty) \rightarrow 0, \quad f(\infty) \rightarrow 0 \quad \text { as } \quad \eta \rightarrow \infty
\end{aligned}
$$

where $m$ is the non-linearity parameter, $M$ is the magnetic parameter, $\lambda$ is the mixed convention parameter, $\varepsilon$ is the velocity ratio parameter, $\operatorname{Pr}$ is the Prandtl number, $R d$ is the radiation parameter, Ec is the Eckert number. Note that $R d=\mathrm{Ec}=0$ correspond to the work of Shen et al. (2015).

The skin friction coefficient $C_{f}$ and the local Nusselt number $\mathrm{Nu}_{x}$ are defined as $C_{f}=\frac{T_{w}(x)}{\rho u_{e}^{2}}$ and $\mathrm{Nu}_{x}=\frac{x q_{w}(x)}{k\left(T_{w}-T_{\infty}\right)^{\prime}}$ respectively, $\mathrm{w}$ the surface stress $T_{w}(x)=\mu\left(\frac{\partial u}{\partial y}\right)_{y=0}$ and $q_{w}(x)$ is the wall heat flux given by Eq.(2.9).

Solving the coupled non linear differential Eqs (2.10), (2.11) together with the boundary conditions Eqs (2.12) and (2.13) numerically by using the sixth order Runge-Kutta method with the shooting technique for some values of the thermo physical parameters involved in the present problem, some graphical results are obtained and discussed in section 3 below.

\section{Results and discussion}

Tables 1 and 2 show that the skin friction $f^{\prime \prime}(0)$ and the heat transfer rate at the surface $\frac{1}{\theta(0)}$ decrease with the radiation parameter $(\mathrm{Rd})$ and Eckert number $(\mathrm{Ec})$. The negative values of the skin friction $f^{\prime \prime}(0)$ for the velocity ratio parameter $\varepsilon>1$ indicate that the sheet exerts a drag force on the fluid and the positive values of the skin friction $f^{\prime \prime}(0)$ for the velocity ratio parameter $\varepsilon<1$ show that the formation of 
the boundary layer depend solely on the stretching sheet. The flow has a boundary layer structure, when the velocity ratio parameter $\varepsilon<1$ and the nonlinearity parameter $m \geq 1$ but has an inverted boundary layer structure when the velocity ratio parameter $\epsilon>1$ and the nonlinearity parameter $m \geq 1$. This indicates that the stretching velocity $u_{w}(x)$ of the surface exceeds the velocity $u_{e}(x)$ of the external stream. Thus, the skin friction coefficient $f^{\prime \prime}(0)$ increases with the increasing values of the nonlinearity parameter $(m)$; injection/suction parameter $(S)$, velocity slip parameter $(\delta)$ and magnetic parameter $(M)$. This follows from the fact that when there is a rise in the strength of the magnetic parameter, the Lorentz force associated with the magnetic field makes the boundary layer thinner.

Table 1. Computation showing values of $f^{\prime \prime}(0)$ and $\frac{1}{\theta(0)}$ with $m, M, \operatorname{Pr}, \operatorname{Rd}, \operatorname{Ec}, S$ and $\varepsilon$ as prescribed parameters when $\varepsilon<1$.

\begin{tabular}{|c|c|c|c|c|c|c|c|c|c|c|}
\hline$m$ & $M$ & $\lambda$ & $\operatorname{Pr}$ & $\mathrm{Rd}$ & Ec & $S$ & $\varepsilon$ & $\delta$ & $f^{\prime \prime}(0)$ & $\frac{1}{\theta(0)}$ \\
\hline 0.6 & 1.0 & -1.0 & 0.72 & 0.1 & 0.1 & 0.5 & 0.1 & 0.5 & 0.43324755 & 0.68412902 \\
\hline 0.8 & 1.0 & -1.0 & 0.72 & 0.1 & 0.1 & 0.5 & 0.1 & 0.5 & 0.60714450 & 0.86084261 \\
\hline 1.0 & 1.0 & -1.0 & 0.72 & 0.1 & 0.1 & 0.5 & 0.1 & 0.5 & 0.71261082 & 1.01790207 \\
\hline 2.0 & 1.0 & -1.0 & 0.72 & 0.1 & 0.1 & 0.5 & 0.1 & 0.5 & 0.95718484 & 1.63433990 \\
\hline 2.0 & 0.0 & -1.0 & 0.72 & 0.1 & 0.1 & 0.5 & 0.1 & 0.5 & 0.90576027 & 1.61412314 \\
\hline 2.0 & 1.0 & -1.0 & 0.72 & 0.1 & 0.1 & 0.5 & 0.1 & 0.5 & 0.95726039 & 1.63487739 \\
\hline 2.0 & 3.0 & -1.0 & 0.72 & 0.1 & 0.1 & 0.5 & 0.1 & 0.5 & 1.03306651 & 1.66398763 \\
\hline 2.0 & 5.0 & -1.0 & 0.72 & 0.1 & 0.1 & 0.5 & 0.1 & 0.5 & 1.08796821 & 1.68396574 \\
\hline 2.0 & 1.0 & -2.0 & 0.72 & 0.1 & 0.1 & 0.5 & 0.1 & 0.5 & 0.87744021 & 1.60540587 \\
\hline 2.0 & 1.0 & -1.0 & 0.72 & 0.1 & 0.1 & 0.5 & 0.1 & 0.5 & 0.95778612 & 1.63865204 \\
\hline 2.0 & 1.0 & 0.0 & 0.72 & 0.1 & 0.1 & 0.5 & 0.1 & 0.5 & 1.03201271 & 1.66863926 \\
\hline 2.0 & 1.0 & 1.0 & 0.72 & 0.1 & 0.1 & 0.5 & 0.1 & 0.5 & 1.10131988 & 1.69604385 \\
\hline 2.0 & 1.0 & 2.0 & 0.72 & 0.1 & 0.1 & 0.5 & 0.1 & 0.5 & 1.16656018 & 1.72134146 \\
\hline 2.0 & 1.0 & -1.0 & 0.72 & 0.1 & 0.1 & 0.5 & 0.1 & 0.5 & 0.95718484 & 1.6343399 \\
\hline 2.0 & 1.0 & -1.0 & 1 & 0.1 & 0.1 & 0.5 & 0.1 & 0.5 & 0.97649466 & 1.98069122 \\
\hline 2.0 & 1.0 & -1.0 & 3 & 0.1 & 0.1 & 0.5 & 0.1 & 0.5 & 1.01382189 & 3.92349716 \\
\hline 2.0 & 1.0 & -1.0 & 5 & 0.1 & 0.1 & 0.5 & 0.1 & 0.5 & 1.02199885 & 5.55620749 \\
\hline 2.0 & 1.0 & -1.0 & 0.72 & 0 & 0.1 & 0.5 & 0.1 & 0.5 & 0.96512313 & 1.75767413 \\
\hline 2.0 & 1.0 & -1.0 & 0.72 & 1 & 0.1 & 0.5 & 0.1 & 0.5 & 0.89392320 & 1.08441954 \\
\hline 2.0 & 1.0 & -1.0 & 0.72 & 3 & 0.1 & 0.5 & 0.1 & 0.5 & 0.78658728 & 0.72184243 \\
\hline 2.0 & 1.0 & -1.0 & 0.72 & 5 & 0.1 & 0.5 & 0.1 & 0.5 & 0.70912958 & 0.5903847 \\
\hline 2.0 & 1.0 & -1.0 & 0.72 & 0.1 & 0.0 & 0.5 & 0.1 & 0.5 & 0.95765482 & 1.64280403 \\
\hline 2.0 & 1.0 & -1.0 & 0.72 & 0.1 & 1.0 & 0.5 & 0.1 & 0.5 & 0.95268695 & 1.55774536 \\
\hline 2.0 & 1.0 & -1.0 & 0.72 & 0.1 & 3.0 & 0.5 & 0.1 & 0.5 & 0.94059360 & 1.38485403 \\
\hline 2.0 & 1.0 & -1.0 & 0.72 & 0.1 & 5.0 & 0.5 & 0.1 & 0.5 & 0.92443242 & 1.2083549 \\
\hline 2.0 & 1.0 & -1.0 & 0.72 & 0.1 & 0.1 & -1.0 & 0.1 & 0.5 & 0.53832521 & 0.72608092 \\
\hline 2.0 & 1.0 & -1.0 & 0.72 & 0.1 & 0.1 & -0.5 & 0.1 & 0.5 & 0.70838863 & 1.00907493 \\
\hline 2.0 & 1.0 & -1.0 & 0.72 & 0.1 & 0.1 & 0.0 & 0.1 & 0.5 & 0.84383107 & 1.31047035 \\
\hline 2.0 & 1.0 & -1.0 & 0.72 & 0.1 & 0.1 & 0.5 & 0.1 & 0.5 & 0.95726039 & 1.63487739 \\
\hline 2.0 & 1.0 & -1.0 & 0.72 & 0.1 & 0.1 & 1.0 & 0.1 & 0.5 & 1.05290596 & 1.98108745 \\
\hline 2.0 & 1.0 & -1.0 & 0.72 & 0.1 & 0.1 & 0.5 & 0.1 & U & 2.00129219 & 1.37106676 \\
\hline 2.0 & 1.0 & -1.0 & 0.72 & 0.1 & 0.1 & 0.5 & 0.1 & 0.5 & 0.95718484 & 1.6343399 \\
\hline 2.0 & 1.0 & -1.0 & 0.72 & 0.1 & 0.1 & 0.5 & 0.1 & 1 & 0.61605802 & 1.7004017 \\
\hline 2.0 & 1.0 & -1.0 & 0.72 & 0.1 & 0.1 & 0.5 & 0.1 & 3 & 0.25197991 & 1.76350408 \\
\hline
\end{tabular}


Table 2. Computation showing values of $f^{\prime \prime}(0)$ and $\frac{1}{\theta(\theta)}$ with $m, M, \operatorname{Pr}, \operatorname{Rd}, \mathrm{Ec}, S$ and $\varepsilon$ as prescribed parameters when $\varepsilon>1$.

\begin{tabular}{|c|c|c|c|c|c|c|c|c|c|c|}
\hline$M$ & $M$ & $\lambda$ & $\operatorname{Pr}$ & $R d$ & Ec & $S$ & $\varepsilon$ & $\delta$ & $f^{\prime \prime}(0)$ & $\frac{1}{\theta(0)}$ \\
\hline 0.6 & 1.0 & -1.0 & 0.72 & 0.1 & 0.1 & 0.5 & 2 & 0.5 & -1.23320442 & 0.84676021 \\
\hline 0.8 & 1.0 & -1.0 & 0.72 & 0.1 & 0.1 & 0.5 & 2 & 0.5 & -1.19285255 & 1.06868916 \\
\hline 1.0 & 1.0 & -1.0 & 0.72 & 0.1 & 0.1 & 0.5 & 2 & 0.5 & -1.18629736 & 1.25772956 \\
\hline 2.0 & 1.0 & -1.0 & 0.72 & 0.1 & 0.1 & 0.5 & 2 & 0.5 & -1.24453308 & 1.96339134 \\
\hline 2.0 & 0.0 & -1.0 & 0.72 & 0.1 & 0.1 & 0.5 & 2 & 0.5 & -1.21621884 & 1.97310656 \\
\hline 2.0 & 1.0 & -1.0 & 0.72 & 0.1 & 0.1 & 0.5 & 2 & 0.5 & -1.24450448 & 1.96372378 \\
\hline 2.0 & 3.0 & -1.0 & 0.72 & 0.1 & 0.1 & 0.5 & 2 & 0.5 & -1.29106348 & 1.94878452 \\
\hline 2.0 & 5.0 & -1.0 & 0.72 & 0.1 & 0.1 & 0.5 & 2 & 0.5 & -1.32830397 & 1.93732309 \\
\hline 2.0 & 1.0 & -2.0 & 0.72 & 0.1 & 0.1 & 0.5 & 2 & 0.5 & -1.29387864 & 1.94769676 \\
\hline 2.0 & 1.0 & -1.0 & 0.72 & 0.1 & 0.1 & 0.5 & 2 & 0.5 & -1.24430614 & 1.96625134 \\
\hline 2.0 & 1.0 & 0.0 & 0.72 & 0.1 & 0.1 & 0.5 & 2 & 0.5 & -1.19659273 & 1.98386222 \\
\hline 2.0 & 1.0 & 1.0 & 0.72 & 0.1 & 0.1 & 0.5 & 2 & 0.5 & -1.15054158 & 2.00063683 \\
\hline 2.0 & 1.0 & 2.0 & 0.72 & 0.1 & 0.1 & 0.5 & 2 & 0.5 & -1.10598854 & 2.01666415 \\
\hline 2.0 & 1.0 & -1.0 & 0.72 & 0.1 & 0.1 & 0.5 & 2 & 0.5 & -1.24453308 & 1.96339134 \\
\hline 2.0 & 1.0 & -1.0 & 1 & 0.1 & 0.1 & 0.5 & 2 & 0.5 & -1.23167007 & 2.39532219 \\
\hline 2.0 & 1.0 & -1.0 & 3 & 0.1 & 0.1 & 0.5 & 2 & 0.5 & -1.20772220 & 4.78056534 \\
\hline 2.0 & 1.0 & -1.0 & 5 & 0.1 & 0.1 & 0.5 & 2 & 0.5 & -1.20271982 & 6.72050059 \\
\hline 2.0 & 1.0 & -1.0 & 0.72 & 0 & 0.1 & 0.5 & 2 & 0.5 & -1.23921710 & 2.11724772 \\
\hline 2.0 & 1.0 & -1.0 & 0.72 & 1 & 0.1 & 0.5 & 2 & 0.5 & -1.28784764 & 1.27909914 \\
\hline 2.0 & 1.0 & -1.0 & 0.72 & 3 & 0.1 & 0.5 & 2 & 0.5 & -1.36383125 & 0.83105127 \\
\hline 2.0 & 1.0 & -1.0 & 0.72 & 5 & 0.1 & 0.5 & 2 & 0.5 & -1.42050867 & 0.66816274 \\
\hline 2.0 & 1.0 & -1.0 & 0.72 & 0.1 & 0.0 & 0.5 & 2 & 0.5 & -1.24422719 & 1.97389495 \\
\hline 2.0 & 1.0 & -1.0 & 0.72 & 0.1 & 1.0 & 0.5 & 2 & 0.5 & -1.24747310 & 1.86791895 \\
\hline 2.0 & 1.0 & -1.0 & 0.72 & 0.1 & 3.0 & 0.5 & 2 & 0.5 & -1.25551243 & 1.64905882 \\
\hline 2.0 & 1.0 & -1.0 & 0.72 & 0.1 & 5.0 & 0.5 & 2 & 0.5 & -1.26667252 & 1.41883920 \\
\hline 2.0 & 1.0 & -1.0 & 0.72 & 0.1 & 0.1 & -1.0 & 2 & 0.5 & -1.06207493 & 1.28855164 \\
\hline 2.0 & 1.0 & -1.0 & 0.72 & 0.1 & 0.1 & -0.5 & 2 & 0.5 & -1.12266016 & 1.48009367 \\
\hline 2.0 & 1.0 & -1.0 & 0.72 & 0.1 & 0.1 & 0.0 & 2 & 0.5 & -1.18401357 & 1.70517250 \\
\hline 2.0 & 1.0 & -1.0 & 0.72 & 0.1 & 0.1 & 0.5 & 2 & 0.5 & -1.24450448 & 1.96372378 \\
\hline 2.0 & 1.0 & -1.0 & 0.72 & 0.1 & 0.1 & 1.0 & 2 & 0.5 & -1.30259268 & 2.25397393 \\
\hline 2.0 & 1.0 & -1.0 & 0.72 & 0.1 & 0.1 & 0.5 & 2 & 0 & -3.28425998 & 2.12988034 \\
\hline 2.0 & 1.0 & -1.0 & 0.72 & 0.1 & 0.1 & 0.5 & 2 & 0.5 & -1.24453308 & 1.96339134 \\
\hline 2.0 & 1.0 & -1.0 & 0.72 & 0.1 & 0.1 & 0.5 & 2 & 1 & -0.77753047 & 1.90968646 \\
\hline 2.0 & 1.0 & -1.0 & 0.72 & 0.1 & 0.1 & 0.5 & 2 & 3 & -0.31278848 & 1.84891810 \\
\hline
\end{tabular}

The effects of the radiation parameter $R d$ on the temperature profile are shown in Fig.2. In Fig.2, increase in the radiation $R d$ increases the temperature, thermal boundary layer thickness and the wall temperature $\theta(0)$. So, the heat transfer rate $1 / \theta(\theta)$ at the surface will decrease as the radiation $R d$ increases.

The effects of the mixed convection parameter $\lambda$ on the velocity and temperature profiles are shown in Figs 3 and 4. In Fig.3, the velocity boundary layer thickness increases with the mixed convection parameter $\lambda$ for $\varepsilon>1$ but decreases with the mixed convection parameter $\lambda$ for $\varepsilon<1$ while the velocity field $f^{\prime}(\eta)$ is an increasing function of the mixed convection parameter $\lambda$ for $\varepsilon<1$ and $\varepsilon>1$. 


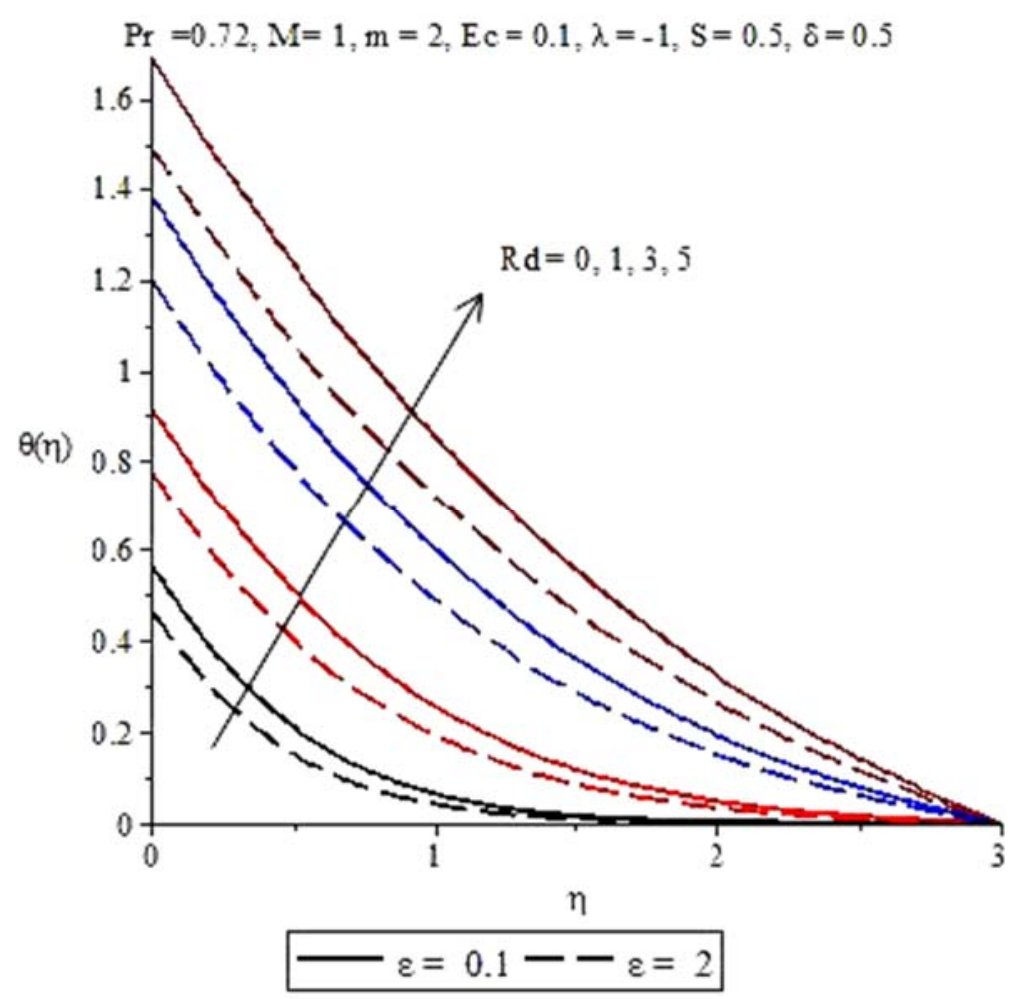

Fig.2. Temperature profile $\theta(\eta)$ for different values of $R d$.

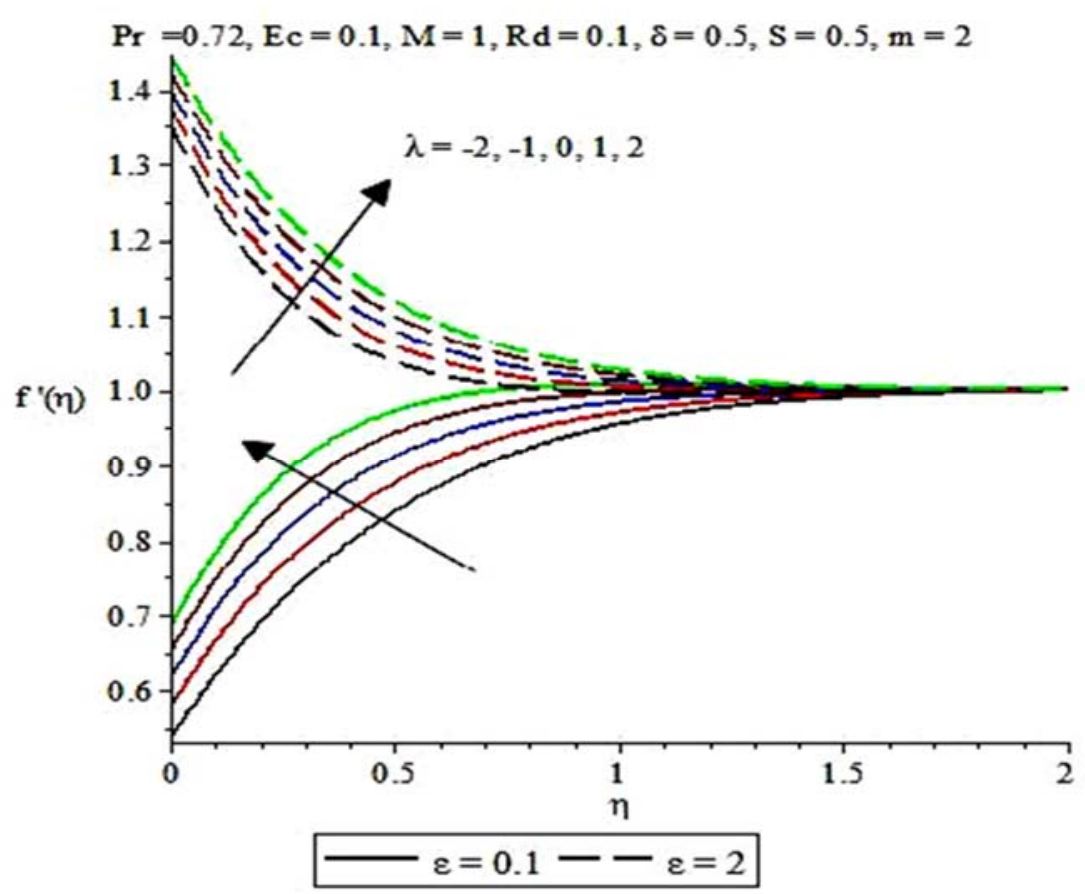

Fig.3. Velocity profile $f^{\prime}(\eta)$ for different values of $\lambda$. 


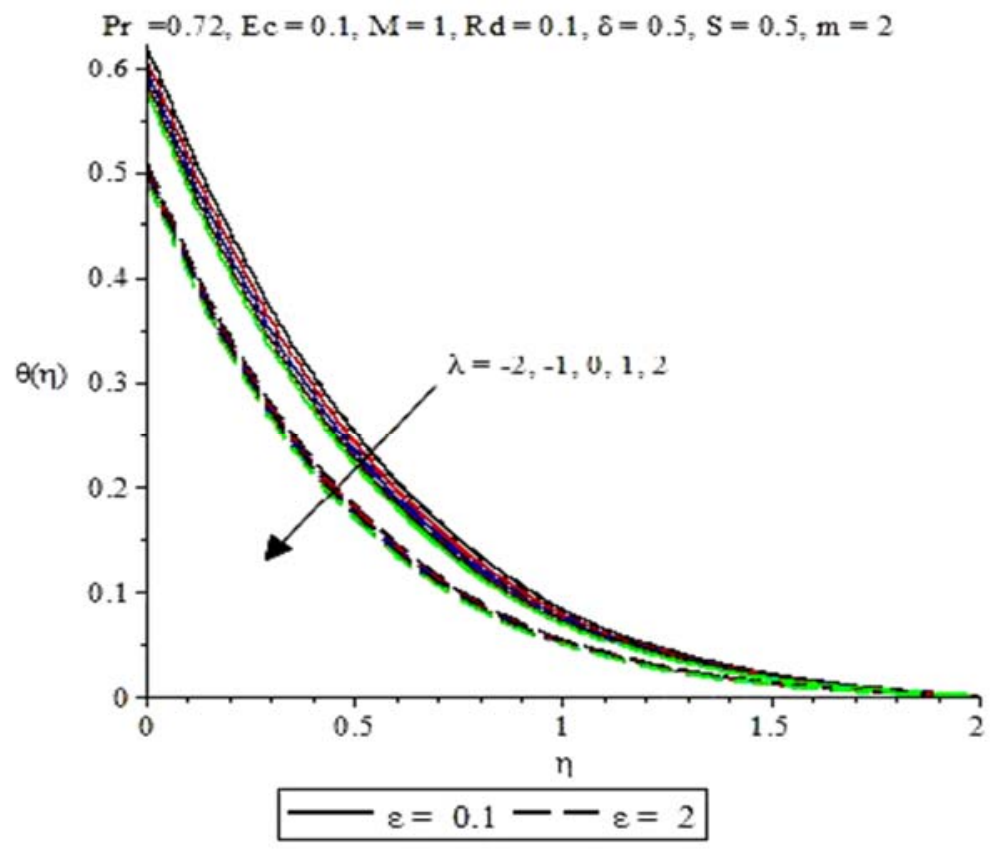

Fig.4. Temperature profile $\theta(\eta)$ for different values of $\lambda$.

In Fig.4, the thermal boundary layer thickness decreases with the mixed convection parameter $\lambda$. So, the wall temperature $\theta(0)$ decreases and the heat transfer rate $1 / \theta(0)$ at the surface increases.

Figures 5 shows the effects of the Eckert number Ec on the temperature profiles. In Fig.5, an increase in the Eckert number Ec corresponds to an increase in the temperature and the thermal boundary layer thickness. So, the wall temperature $\theta(\theta)$ will increase and thereby decreasing the heat transfer rate at the surface $1 / \theta(0)$.

Figures 6-9 illustrate the effects of the nonlinearity parameter $(m)$, injection/suction parameter $(S)$, velocity slip parameter $(\delta)$ and magnetic parameter $(M)$ for velocity ratio parameters $\varepsilon<1$ and $\varepsilon>1$. In Fig.6, the velocity boundary layer thickness decreases with increasing nonlinearity parameter $(m)$, for $\varepsilon>1$ but increases with increasing nonlinearity parameter $(m)$ for $\varepsilon<1$. Since the heat transfers rate at the surface $\frac{1}{\theta(0)}$ increases positively with the nonlinearity parameter $m$, it shows that the heat is transferred from the hot sheet to the cold fluid. In Figs 7-9, the velocity boundary layer thickness decreases with increasing injection/suction $(S)$, velocity slip $(\delta)$ and magnetic $(M)$ parameters for $\varepsilon<1$ which shows an increasing magnitude of the velocity gradient at the surface. Also, Figs 7-9 show that the velocity boundary layer thickness increases with increasing injection/suction $(S)$, velocity slip parameter $(\delta)$ and magnetic parameter $(M)$ for velocity ratio parameter $\varepsilon<1$ but decreases with increasing injection/suction $(S)$, velocity slip $(\delta)$ and magnetic $(M)$ parameters for the velocity ratio parameter $\varepsilon>1$. As shown in the diagram, the temperature decreases to zero monotonically as the independent variable $\eta$ increases which satisfies the field boundary condition $\theta(\infty)=0$. This shows that the temperature and thermal boundary layer thickness is lower for $\varepsilon>1$ and higher for $\varepsilon<1$ when the parameters are constant. In Figs 10-11, the temperature and thermal boundary layer thickness decrease with increasing nonlinearity parameter $(m)$ and injection/suction parameter $(S)$. Thus, the wall temperature $\theta(0)$ will decrease and the heat transfer rate at the surface will increase for $\varepsilon<1$ and $\varepsilon>1$. In Figs 13-13, the wall temperature and thermal boundary layer thickness decrease with increasing velocity slip parameter $(\delta)$ and magnetic parameter $(M)$ for the velocity ratio 
parameter $\varepsilon<1$ and vice versa for $\varepsilon>1$. Thus, the heat transfer rate at the surface increases with velocity slip $(\delta)$ or magnetic $(M)$ parameters for velocity ratio $\varepsilon<1$ and vice versa for velocity ratio $\varepsilon>1$.

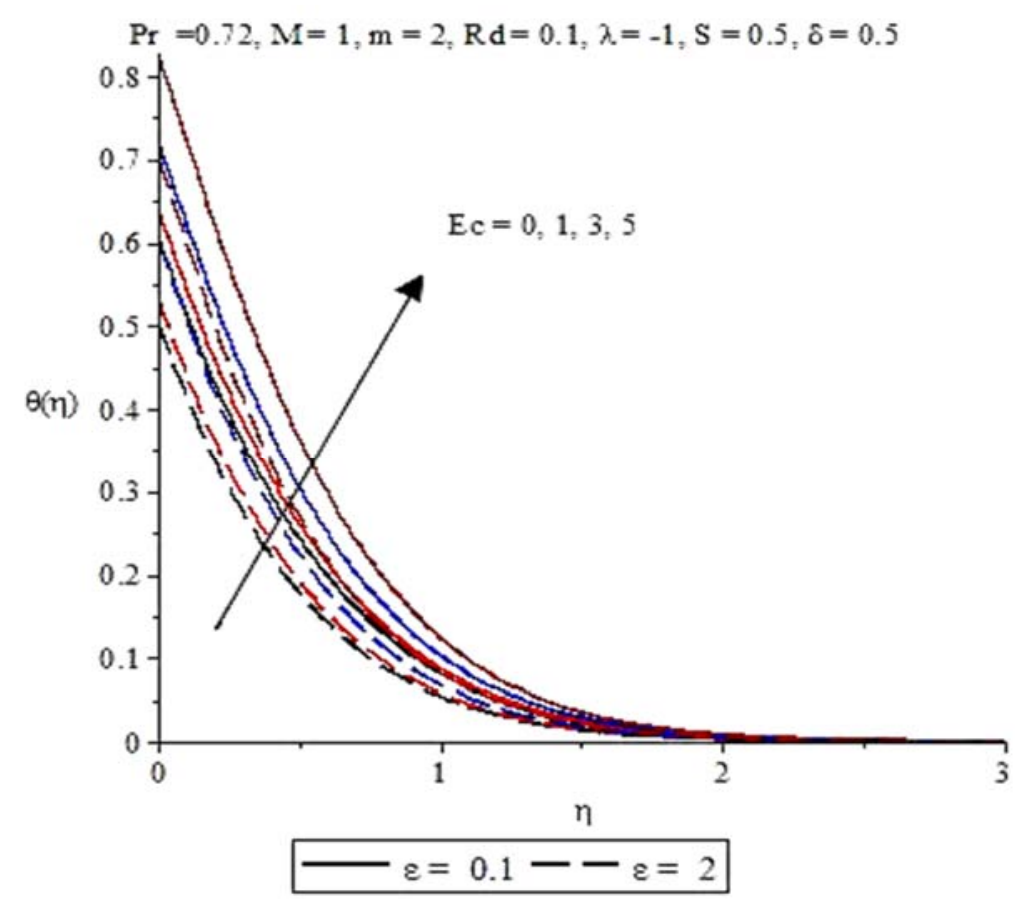

Fig.5. Temperature profile $\theta(\eta)$ for different values of Ec.

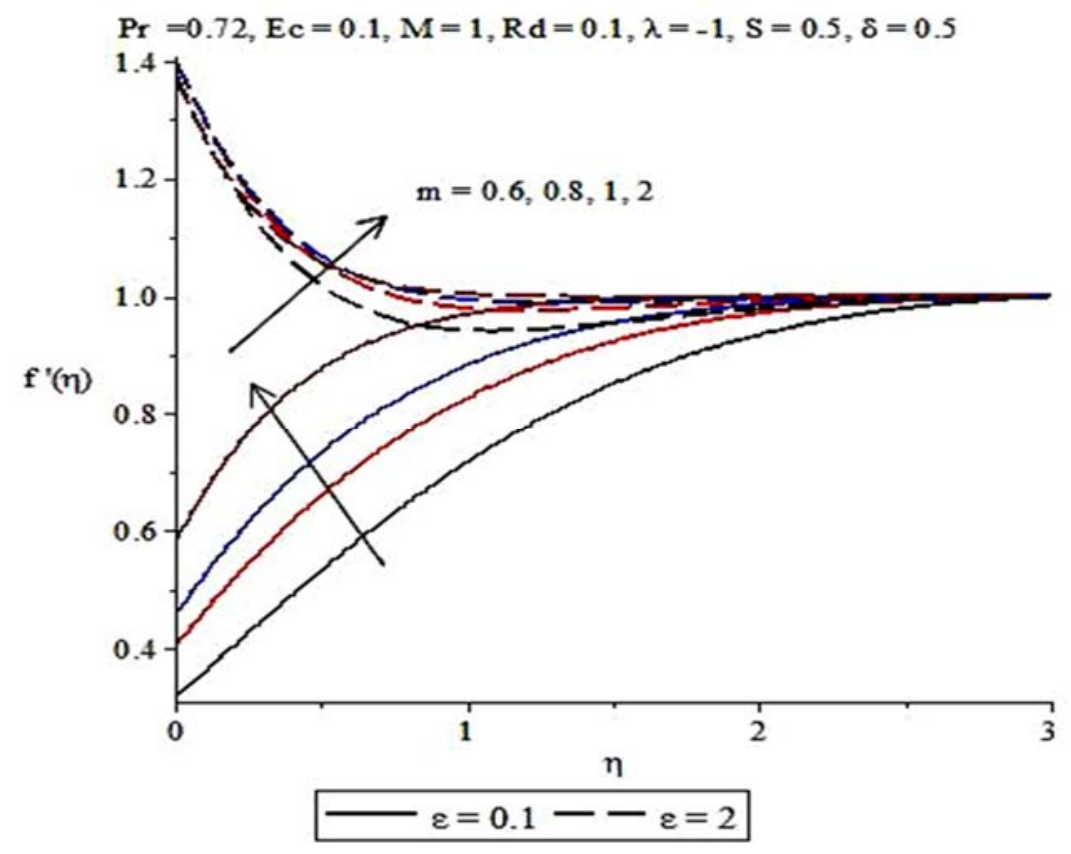

Fig.6. Velocity profile $f^{\prime}(\eta)$ for different values of $m$. 


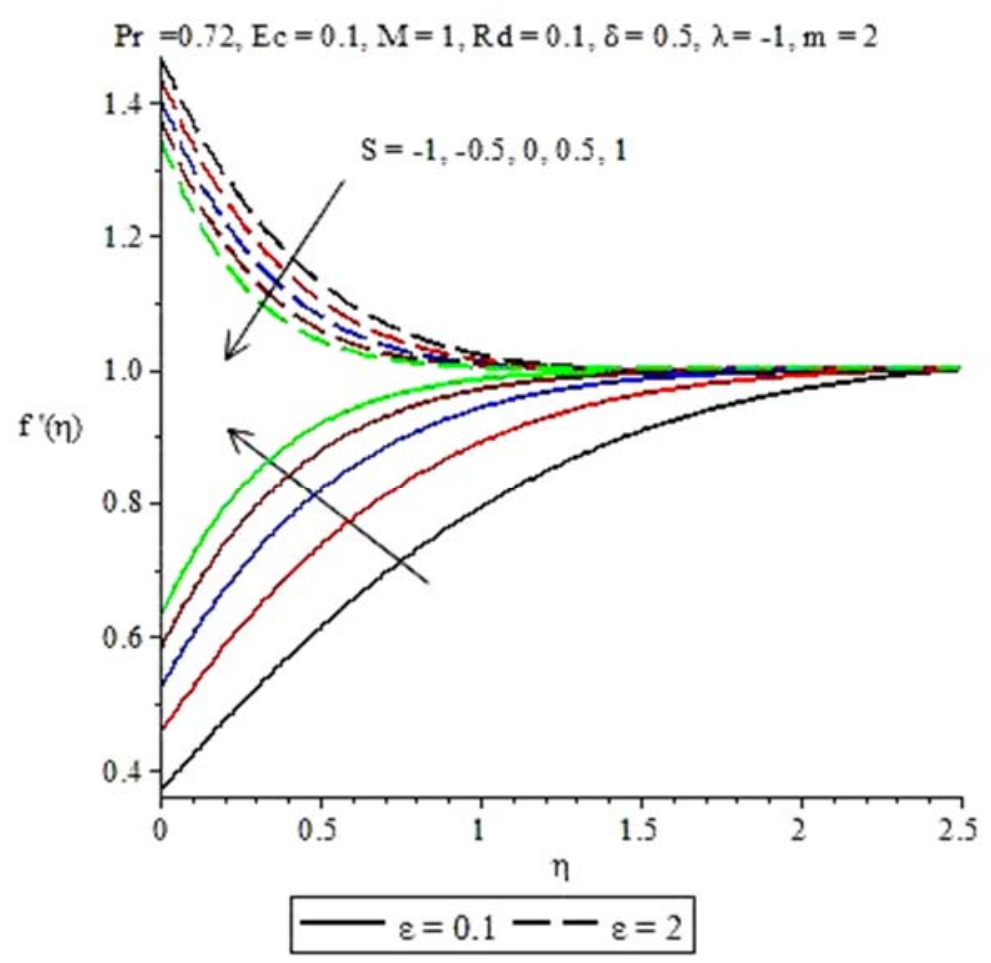

Fig.7. Velocity profile $f^{\prime}(\eta)$ for different values of $S$.

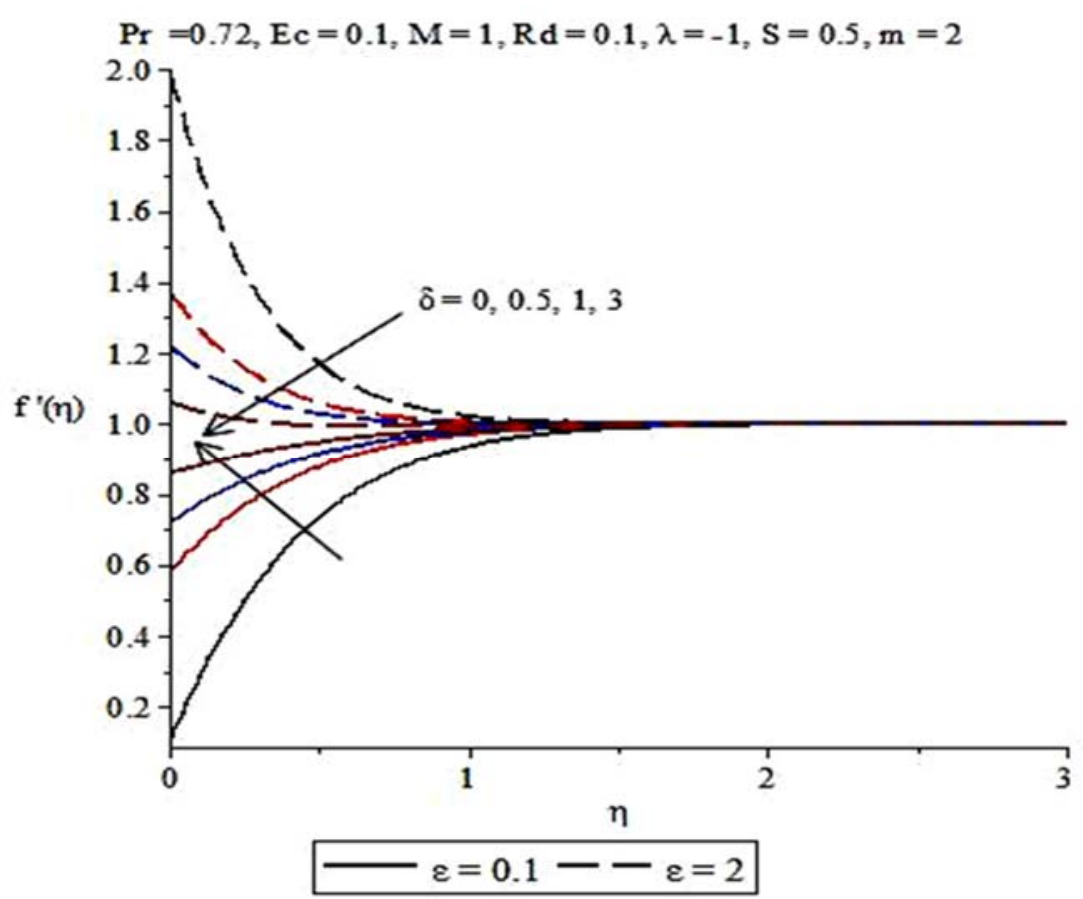

Fig.8. Velocity profile $f^{\prime}(\eta)$ for different values of $\delta$. 


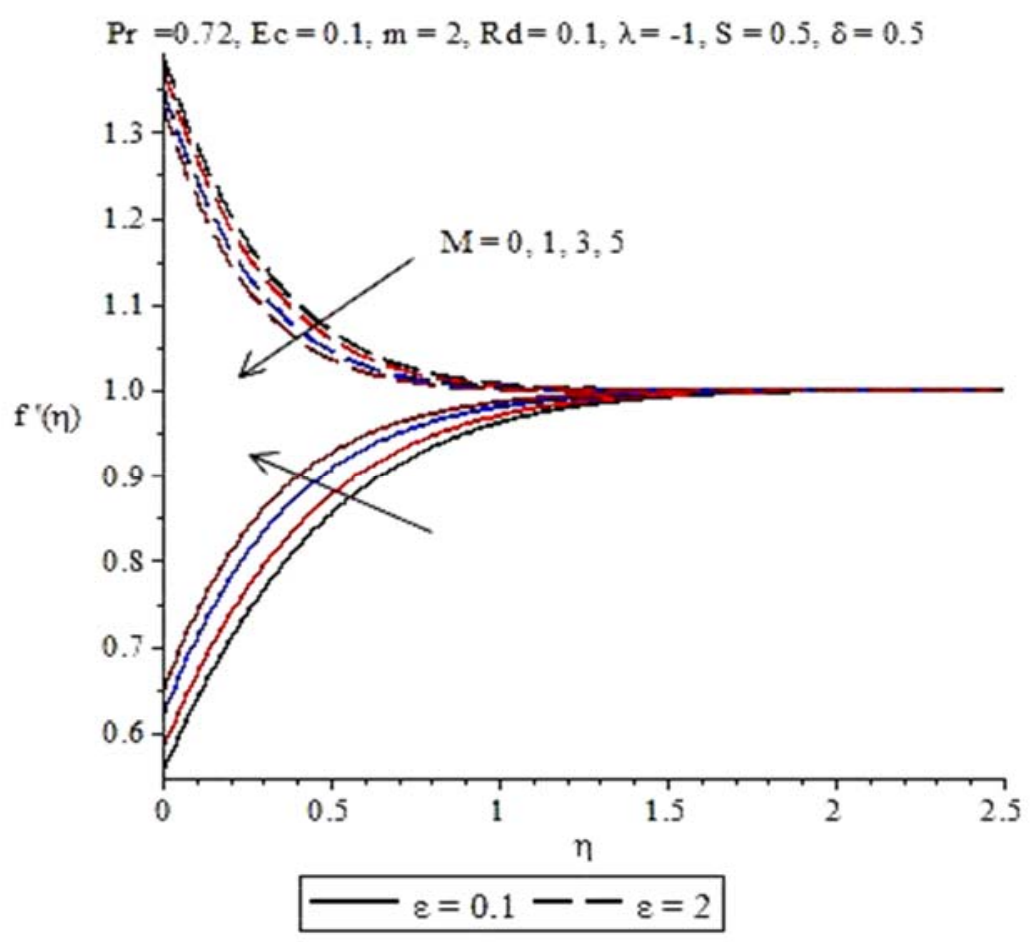

Fig.9. Velocity profile $f^{\prime}(\eta)$ for different values of $M$.

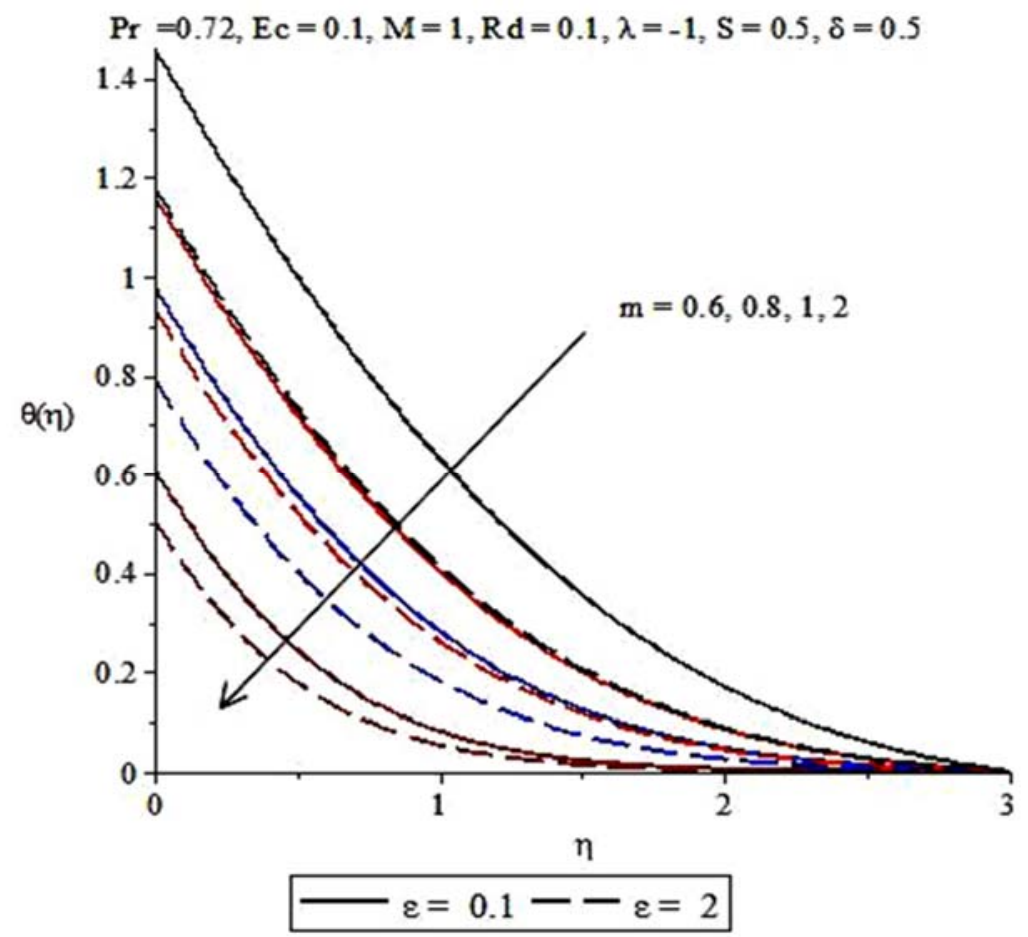

Fig.10. Temperature profile $\theta(\eta)$ for different values of $m$. 


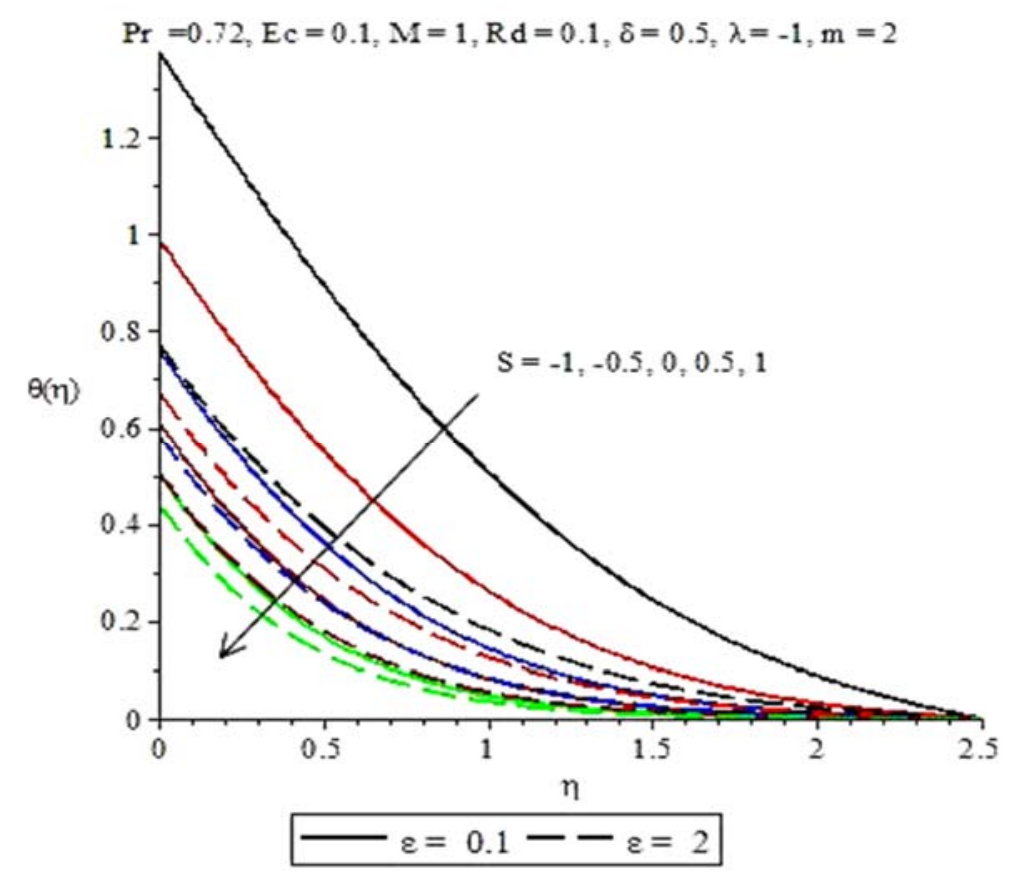

Fig.11. Temperature profile $\theta(\eta)$ for different values of $S$.

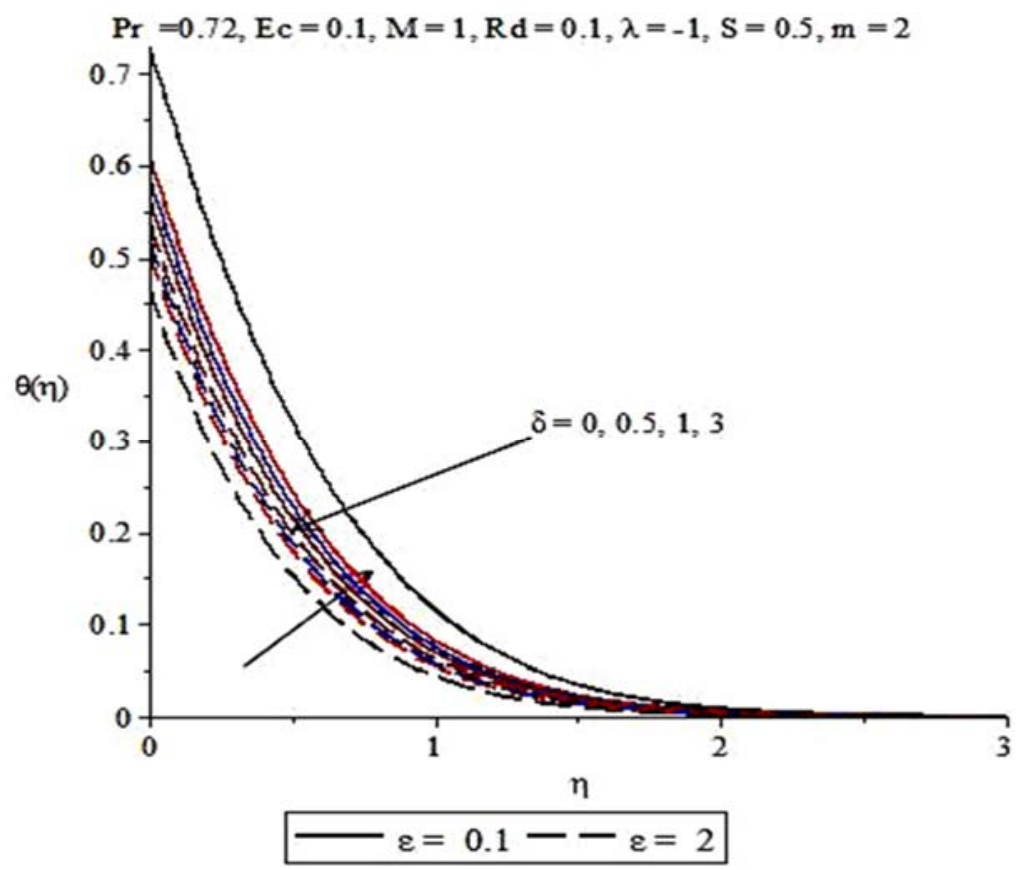

Fig.12. Temperature profile $\theta(\eta)$ for different values of $\delta$. 


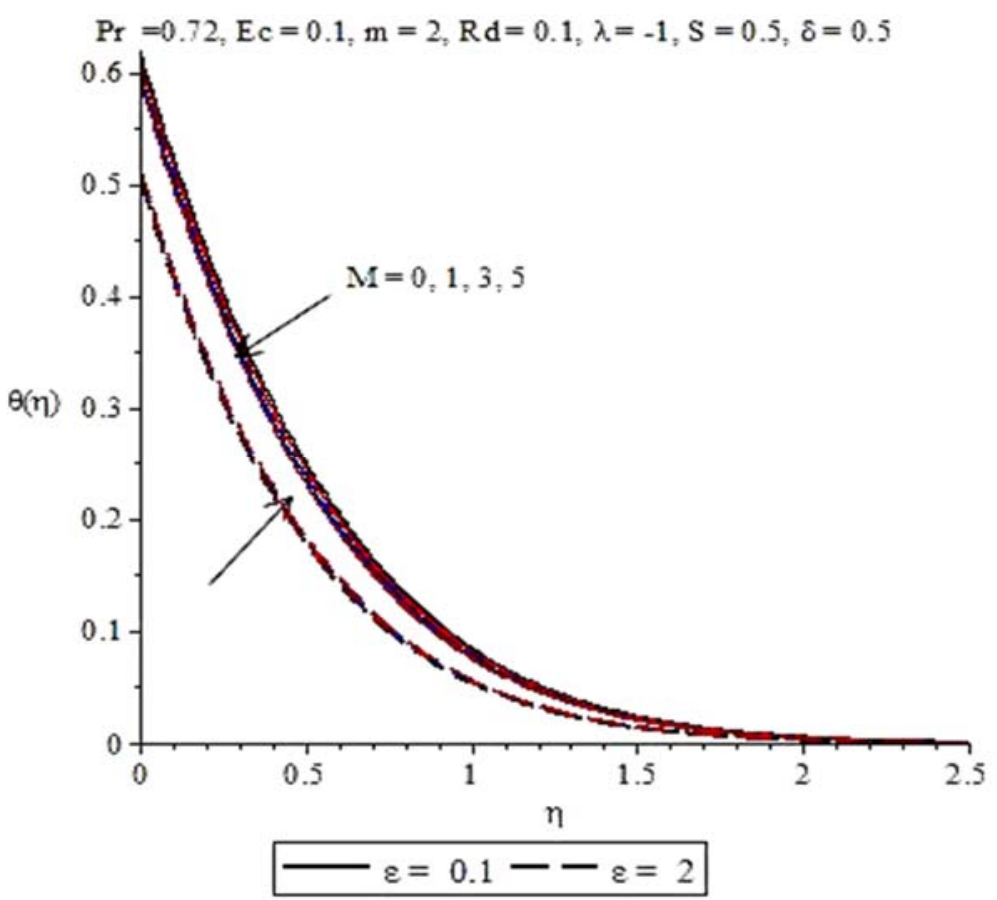

Fig.13. Temperature profile $\theta(\eta)$ for different values of $M$.

\section{Conclusion}

This work considers the mixed convection effects and heat transfer rate at the surface for an MHD flow near a stagnation point on a nonlinear vertical stretching sheet using the fourth order Runge Kutta method. The graphical results show that:

(i) Increase in radiation increases the temperature, thermal boundary layer thickness and the wall temperature thereby reducing the heat transfer rate at the surface.

(ii) The velocity boundary layer thickness increases with the mixed convection parameter for $\varepsilon>1$ but decreases with the mixed convection parameter for $\varepsilon<1$.

(iii) The heat transfer rate at the surface increases as the thermal boundary layer and the wall temperature decrease with the mixed convection parameter.

(iv) The heat transfer rate at the surface decreases with an increase in the Eckert number, thermal boundary layer thickness and the wall temperature.

(v) The velocity boundary layer thickness decreases with an increase in the injection/suction, velocity slip and magnetic parameters for $\varepsilon>1$ which shows an increasing magnitude of the velocity gradient at the surface.

(vi) The velocity boundary layer thickness increases with increasing injection/suction, velocity slip and magnetic parameters for $\varepsilon<1$ but decreases with increasing injection/suction, velocity slip and magnetic parameters for $\varepsilon>1$.

(vii) The velocity boundary layer thickness decreases with increasing nonlinearity parameter for $\varepsilon>1$ but increases with increasing nonlinearity parameter for $\varepsilon<1$.

(viii) The heat transfer rate at the surface increases for $\varepsilon<1$ and $\varepsilon>1$ when the nonlinearity and injection/suction parameter increase due to a decrease in the wall temperature and thermal boundary layer thickness.

(ix) The heat transfer rate at the surface increases with velocity slip or magnetic parameter for the velocity ratio $\varepsilon<1$ and vice versa for the velocity ratio $\varepsilon>1$. 


\section{Acknowledgment}

The authors appreciate the referees comments and their useful suggestions which improved the quality of the paper.

\section{Nomenclature}

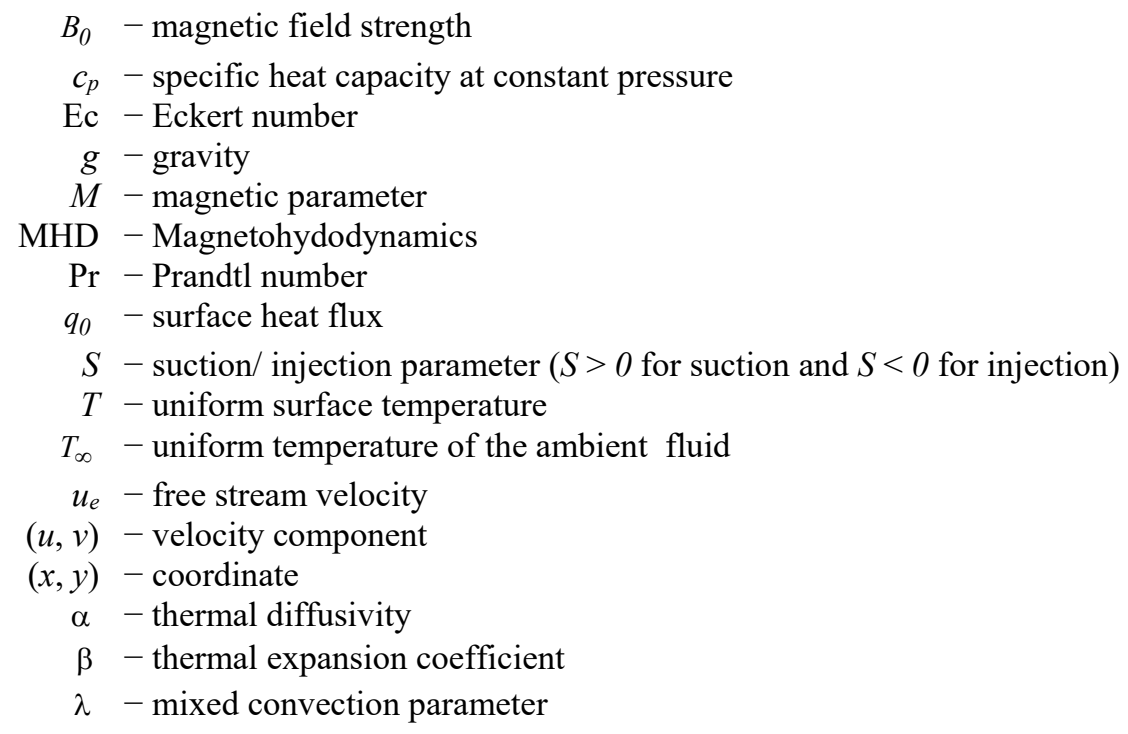

\section{References}

[1] Ali F.M., Nazar R., Arin N.N and Pop I. (2014): Mixed convection stagnation-point flow on vertical stretching shet with external magnetic field. - Appl. Math. Mech., vol.35, No.2, pp.155-166.

[2] Ali F. and Zaib A. (2019): Unsteady flow of an Eyring-Powell Nano fluid near stagnation point past a convectively heated stretching sheet. - Arab Journal of Basic Applied Sciences, Taylor and Francis, vol.26, No.1, pp.215-224.

[3] Akyildiz F.T. and Siginer D.A. (2010): Galerkin-Legendre spectral method for the velocity and thermal boundary layers over a non-linearly stretching sheet. - Nonlinear Anal., Real World Appl., vol.11, No.2, pp.735-741.

[4] Ashraf M.B., Hayat T. and Alsaedi A. (2015): Three-dimensional flow of Eyring-Powell nanofluid by convectively heated exponentially stretching sheet. - Eur. Phys. J. Plus, vol.130, No.1, pp.1-16.

[5] Akyildiz F.T., Siginer D.A., Vajravelu K., Cannon J.R. and Van Gorder R.A. (2010): Similarity solutions of the boundary layer equations for a nonlinearly stretching sheet. - Math. Methods Appl. Sci., vol.33, No.5, pp.601-606.

[6] Das S., Jana R.N. and Makinda O.D. (2014): MHD boundary layer slip flow and heat transfer of nanofluid past a vertical stretching sheet with non-uniform heat generation/absorption. - Int. J. Nanosci., vol.13, No.3, 1450019.

[7] Das M., Mahatha B.K. and Nandkeolyar R. (2015): Mixed convection and nonlinear radiation in the stagnation point Nanofluid flow towards a stretching sheet with homogeneous-heterogeneous reaction effects. - Procedia Engineering, vol.127, Elsevier, Science Direct, pp.1018-1025.

[8] Dhanai R.P., Rana P. and Kumar L. (2015): Multiple solutions of MHD boundary layer flow and heat transfer behavior of nanofluids induced by a power-law stretching/shrinking permeable sheet with viscous dissipation.Powder Technol., vol.273, pp.62-70.

[9] Fauzi N.F., Ahmad S. and Pop I. (2015): Stagnation-point flow and heat transfer over a nonlinear shrinking sheet with slip effects. - Alexandra Engineering Journal, Elsevier, Science Direct, vol.54, No.4, pp.929-939.

[10] Govardhan K., Nagaraju G., Kaladhar K. and Balasiddulu M. (2015): MHD and radiation effects on mixed convection unsteady flow of micropolar fluid over a stretching sheet. - Procedia of Computer Science, Elsevier, 
Science Direct, vol.57, pp.65-76.

[11] Ishak A., Jafar K., Nazar R. and Pop I. (2009): MHD stagnation point flow towards a stretching sheet. - Physica A vol.388, No.13, pp.3377-3383.

[12] Ishak A., Nazar R. and Pop I. (2010): MHD mixed convection boundary layer flow towards a stretching vertical surface with constant wall temperature. - Int. J. Heat and Mass Transfer, vol.53, No.23-24, pp.5330-5334.

[13] Khan Z.H., Khan W.A., Qasim M. and Shah I.A. (2014): MHD stagnation point ferro fluid flow and heat transfer toward a stretching sheet. - IEEE Trans. Nanotechnol., vol.13, No.1, pp.35-40.

[14] Kham M.I., Tamoor M., Hayat T. and Alsaedi A. (2017): MHD boundary layer thermal slip flow by nonlinearly stretching cylinder with suction/blowing and radiation. - Results in Physics, Elsevier, Science Direct, vol.7, pp.1207-1211.

[15] Mabood F., Khan W.A. and Ismail A.M. (2015): MHD boundary layer flow and heat transfer of nanofluids over a nonlinear stretching sheet: a numerical study. - J. Magnetism and Magnetic Materials., Elsevier, vol.374, pp.569-576.

[16] Mahatha B.K., Nandkeolyar R., Nagaraju G. and Das M. (2015): MHD stagnation point flow of a Nano fluid with velocity slip, nonlinear radiation and Newtonian heating. - Procedia Engineering, Elsevier, Science Direct, vol.127, pp.1010-1017.

[17] Makinde O.D. (2012): Heat and mass transfer by MHD mixed convection stagnation point flow toward a vertical plate embedded in a highly porous medium with radiation and internal heat generation. - Meccanica, vol.47, pp.1173-1184.

[18] Makinde O.D., Khan A.H. and Khan Z.H. (2013): Buoyancy effects on MHD stagnation point flow and heat transfer of a nanofluid past a convectively heated stretching/shrinking sheet. - Int. J. Heat Mass Transfer, vol.62, pp.526-533.

[19] Matta A. and Gajjela N. (2018): Order of chemical reaction and convective boundary condition effects on micropolar fluid flow over a stretching sheet. - AIP Advances 8, 115212, doi: 1063/10.1063/1.5053445.

[20] Medikare M., Joga S. and Chidem K.K. (2016): MHD stagnation point flow of a casson fluid over a nonlinearly stretching sheet with viscous dissipation. - American Journal of Computational Mathematics, vol.6, No.1, pp.10.4234/ajcm.2016,61005.

[21] Nagaraju C. and Ramana Muphy J.V. (2013): MHD flow of longitudinal and torsional oscillations of a porous circular cylinder with suction in a couple stress fluid. - International Journal of Mechanics and Engineering, vol.18, No.4, pp.1099-1114.

[22] Nandeppanavar M.M., Kemparaju M.C. and Shakunthala S. (2018): MHD stagnation point slip flow due to a nonlinearly moving surface with effect of non-uniform heat source. - Nonlinear Engineering, Modelling and Applications, DE- Gruyter, vol.8, No.1, doi:10.1515.

[23] Shen M., Wang F. and Chen H. (2015): MHD Mixed Convection slip flow near stagnation-point on a nonlinearly vertical stretching sheet. Boundary value problem. - Springer open Journal, No.1, 78.

[24] Shateyi S. and Mabood F. (2017): MHD mixed convection slip flow near a stagnation point on a nonlinearly vertical stretching sheet in the presence of viscous dissipation. - Thermal Science, vol.21, No.6B, pp.2709-2723.

[25] Shateyi S. and Makinde O.D. (2013): Hydromagnetic stagnation-point flow towards a radially stretching convectively heated disk. - Math. Probl. Eng., Article ID 616947.

[26] Shateyi S. and Marewo G.T. (2014): Numerical analysis of unsteady MHD flow near a stagnation point of a twodimensional porous body with heat and mass transfer, thermal transfer and chemical reaction. - Boundary Value Problem, 2014(218).

Received: March 14, 2019

Revised: November 19, 2019 